\title{
Las fuentes jesuitas del Siglo XVIII y su utilidad para el estudio de la movilidad de los cazadores - recolectores del desierto central de Baja California, México.
}

The jesuit sources of tje 18th century and its utility for the study of the mobility of the huntes - gatherers of the central desert of Baja California, México

Jesús Feliberto Zarco Navarro*

Resumen: Los primeros misioneros jesuitas que arribaron al desierto central de la península de Baja California, al noroeste de México, en el siglo XVIII, realizaron descripciones y crónicas sobre las lenguas, costumbres, la cultura material y la forma de organización de los grupos humanos que ahí habitaban. Las cartas, diarios, crónicas y dibujos que realizaron los misioneros durante sus labores de evangelización en la península son de gran utilidad para historiadores, antropólogos y arqueólogos, ya que son fuentes de información que contribuyen sustancialmente al conocimiento sobre las antiguas formas de vida, las estrategias de subsistencia y las formas de movilidad ligadas con la obtención de ciertos recursos a lo largo del año.

Palabras Clave: jesuitas, seminómadas, dieta, estacionalidad, Baja California, cochimí.

\begin{abstract}
The first Jesuit missionaries who arrived to the central desert of the peninsula of Baja California, to the northeast of Mexico, in the eighteenth century, made descriptions and chronicles about the languages, customs, material culture and forms of organization of the human groups that lived there. The letters, diaries, chronicles and drawings made by the missionaries during their work of evangelization in the peninsula are very

\footnotetext{
* Instituto de Investigaciones Antropológicas. Universidad Nacional Autonóma de México. E-mail: maje182@hotmail.com
} 
useful for historians, anthropologists and archaeologists, since they are sources of information that contribute substantially to knowledge about ancient ways of life, subsistence strategies and forms of mobility linked to obtaining certain resources throughout the year.

Keywords: Jesuit, seminomads, diet, seasonality, Baja California, cochimí.

Recibido: 12 de agosto de 2018.

Evaluado: 20 de noviembre de 2018. 


\section{Introducción}

Durante el siglo XVIII se estableció en la península de Baja California, al noroeste de México, el sistema misional jesuita, el cual tenía entre sus objetivos realizar tareas de evangelización a las poblaciones indígenas que ahí habitaban. Durante su estancia en la península diferentes misioneros elaboraron documentos en los cuales describen las formas de vida, costumbres, tradiciones y cultura material de los pobladores que ahí habitaban al momento del contacto con los misioneros. Los documentos jesuitas existentes sobre la península de Baja California, a la cual se suele llamar Antigua California, son considerados importantes fuentes de información de carácter etnológico que permiten conocer más a cerca del pasado indígena, sobre su cultura material, la forma de organización y el entorno en el cual subsistían estos grupos.

Los primeros documentos elaborados por exploradores y misioneros han sido de utilidad para investigadores ${ }^{1}$ como: Pablo L. Martínez (2011), Ignacio del Río (1998, 2000), Rosa E. Rodríguez Tomp (2002), Miguel León-Portilla (2000), Leonardo Varela (2016), María Teresa Uriarte (2013), María de la Luz Gutiérrez (2006), Mauricio Mixco (1978), siendo el autor más reconocido el historiador Michael Mathes (1980, 2010), quien desde la década de los años sesenta del siglo XX puso gran esfuerzo en hacer accesibles abundantes obras impresas del siglo XVI al XIX relacionadas con la historia peninsular (Magaña, 2014). Estos autores desde una perspectiva historiográfica han podido delinear como era el panorama cultural de la península al momento del contacto de las poblaciones prehistóricas con los nuevos grupos humanos que comenzaron a arribar a la península a partir del siglo XVI (Rodríguez, 2002, p. 48).

Para este trabajo se analiza con ayuda tres obras jesuitas del siglo XVIII, la forma de subsistencia de los antiguos grupos peninsulares y su relación con la disponibilidad de recursos alimenticios a lo largo del año; siguiendo una metodología que permita establecer un puente entre la información histórica y arqueológica de la península de Baja California, para generar una conexión explicativa entre el tipo de recursos que recolectaban en las distintas estaciones del año y el tipo de movilidad que practicaban. Esta metodología se basa en la tendencia de que los estudios históricos son "un continuo esfuerzo de comprensión-conocimiento-análisis, que deben llevar al investigador a conocer las tendencias teórico-conceptuales más apropiadas para su proyecto" (Magaña, 2014 , p. 43); por lo tanto, con ese estudio se quiere conocer a partir del principio de analogía entre las fuentes históricas y la percepción arqueológica, como fueron las formas de vida de las poblaciones que habitaron antes de la llegada de los jesuitas en la parte central de la península de Baja California.

\section{La Compañía de Jesús y sus aportes a la linguiística de Baja California}

La región del desierto central es una provincia fisiográfica de condiciones ambientales áridas, localizada entre los paralelos $26^{\circ}$ y $30^{\circ}$ (Figura 1). En esta región se desarrolló hace 1,500 años una tradición cultural de grupos hablantes de la lengua cochimí, quienes subsistieron ante condiciones climáticas áridas y a la geografía áspera del desierto siguiendo un modo de vida seminómada, basando su subsistencia en la caza de animales como venados, liebres, serpientes, roedores, ballenas, caguamas, aves, tiburón, lobos marinos, así como mediante la pesca de diversas especies marinas en las

\footnotetext{
${ }^{1}$ Remito al lector a la bibliografía de este trabajo para la consulta de algunas obras de estos autores.
} 
costas del golfo de California y el océano Pacífico, junto con la recolección de insectos, moluscos y vegetales (Mathes, 1980).

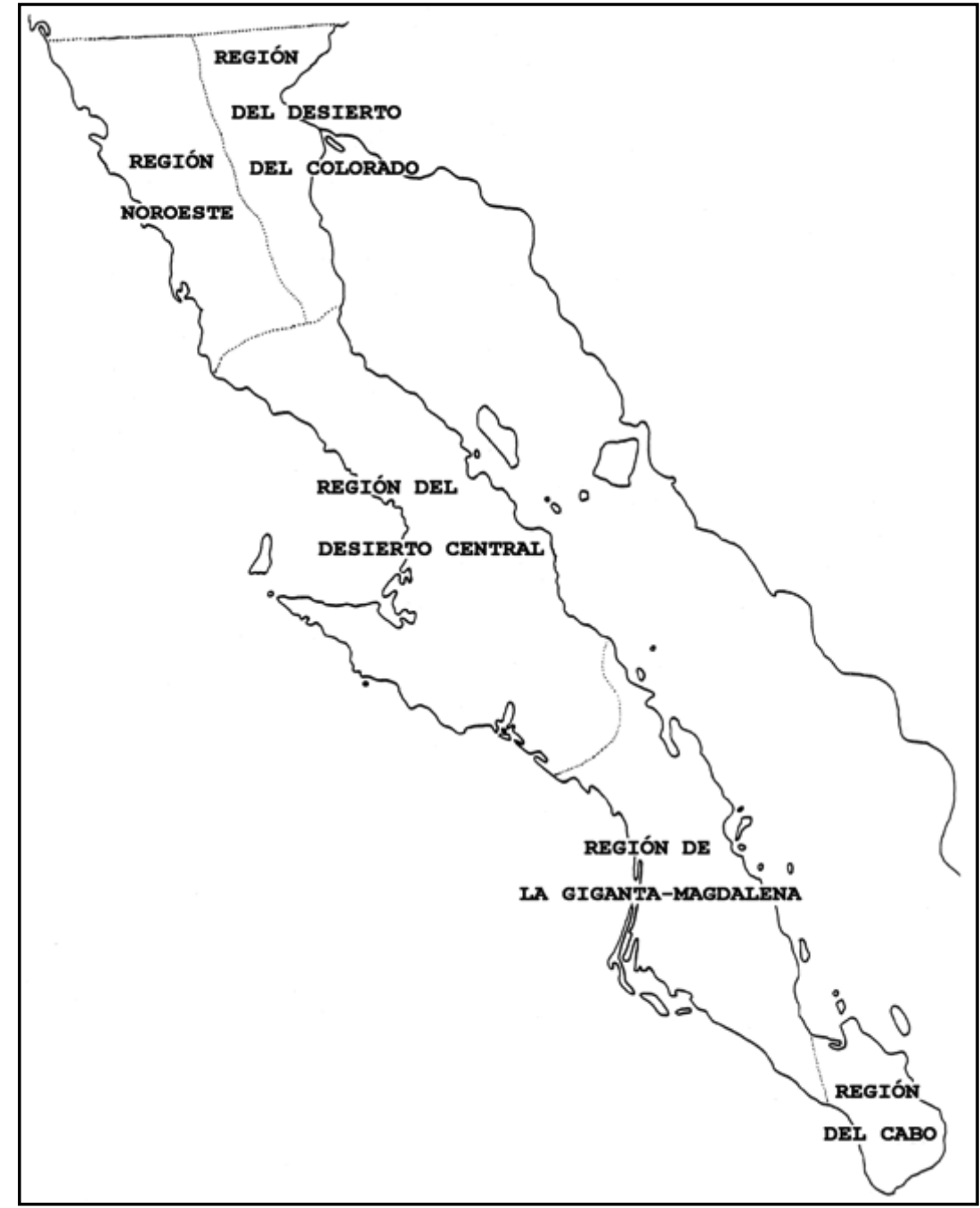

Fig. 1 Regiones de Baja California (Laylander, 2016).

Los primeros datos sobre las poblaciones que habitaban en la península de Baja California fueron recolectados en el siglo XVIII por misioneros de la Compañía de Jesús (Mathes, 2010, p. 57). El establecimiento del sistema misional Jesuita en la península (1697-1768), continuado por la Orden de San Francisco (1768-1773) y la Orden de Predicadores o Dominicos (1773-1855), permitió mediante la observación y participación directa que los misioneros recopilaran datos etnográficos de gran valor, que presentan una visión global de la cultura de los grupos bajacalifornianos (Mathes, 2010). La condición académica de los misioneros jesuitas fue uno de los principales factores para que los datos proporcionados por ellos sean considerados los de mayor importancia dentro del ámbito histórico, ya que documentos elaborados por jesuitas como Juan María Salvatierra, Juan de Ugarte, Clemente Guillén, Sigismundo Taraval, Fernando Consag o Wenceslao Linck presentan un alto nivel de interés científico en la descripción de las costumbres y formas de vida de grupos bajacalifornianos específicos (Mathes, 2010, p. 59).

La mayoría de estos religiosos durante su estancia en la península tomó apuntes, escribió cartas, notas o realizó dibujos motivados por la necesidad de registrar ambientes, sucesos y datos que se presentaban ante ellos en diferentes circunstancias (Varela, 
2016, p. 19). Entre los documentos que los jesuitas generaron se pueden encontrar transcripciones gramaticales del idioma correspondiente al de los grupos indígenas con quienes interactuaban, esto lo hacían con el objetivo de poder realizar las traducciones escritas de las oraciones, los artículos de fe católica o las homilías doctrinales a la lengua de los habitantes locales de cada región en la que se establecía una misión (Mixco, 2010, p. 33). Este tipo de traducciones sirvió para que desde el siglo XVIII, Sigismundo Taraval pudiera determinar la existencia de tres lenguas distintas en la península de Baja California: la pericú al sur, la guaycura y uchití en la región de Loreto, y la cochimí al centro-norte de la península (Del Barco 1973, p. 171) (Figura 2).

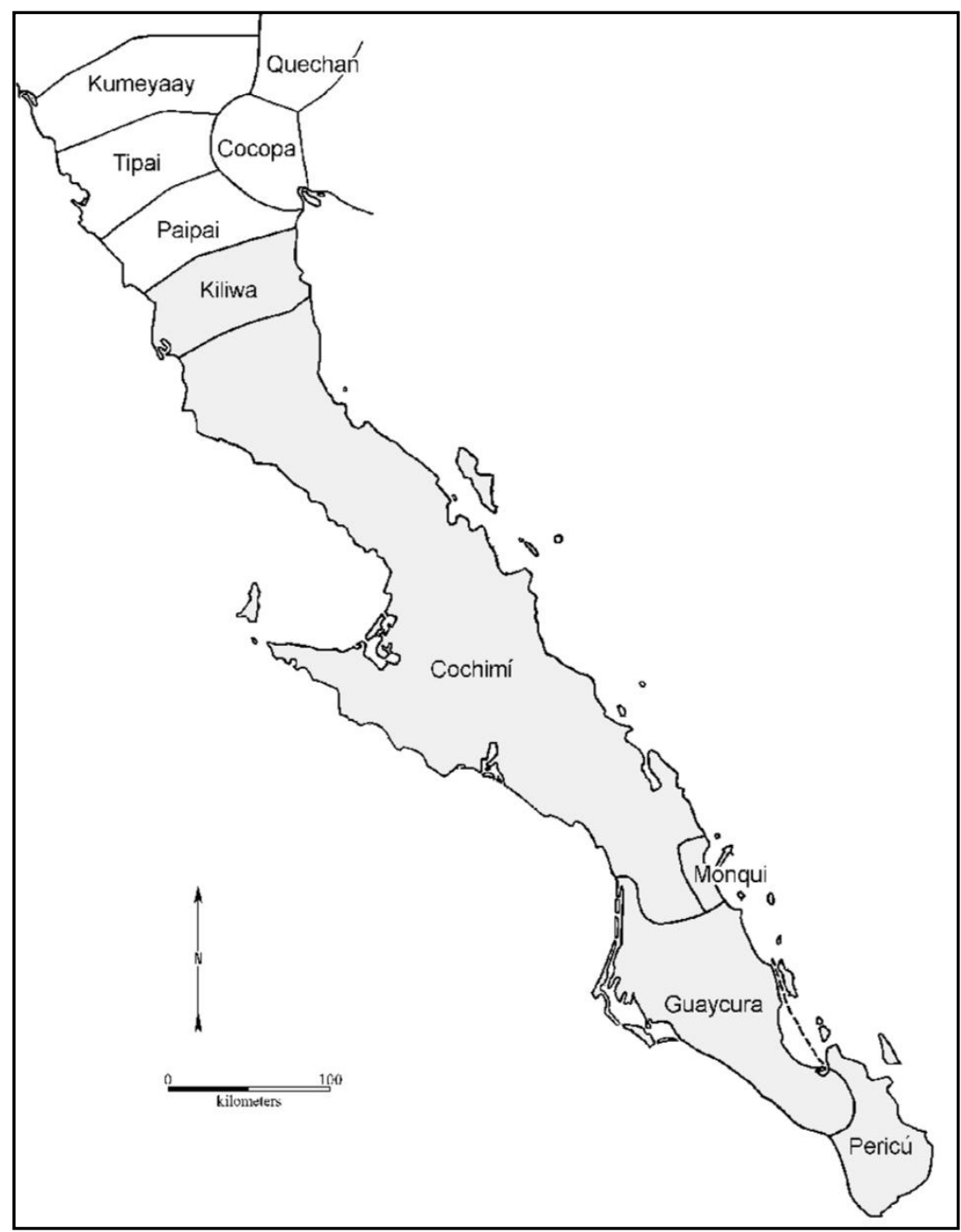

Fig. 2 Lenguas peninsulares (Laylander, 2001).

Las lenguas pericú, guaycura y uchití fueron las primeras con las que los misioneros jesuitas tuvieron contacto, pues se encontraban en el extremo sur de la península, el cual, durante el siglo XVIII, era el mejor explorado y el que contaba con rutas de navegación ya establecidas desde puertos en la península, así como los localizados al este de la península, como el de Sinaloa; desde donde el padre Juan María Salvatierra había realizado la primera expedición hacía la península en el año 1683 para comenzar el establecimiento del sistema misional (Varela, 2016). Sin embargo, los misioneros no tenían claro hasta que región se encontraban los hablantes de la lengua cochimí, en principio se consideraba que estos grupos se encontraban únicamente desde la misión de San 
Javier, en Loreto, por todo el territorio al norte que había sido explorado por los jesuitas hasta 1716, el cual correspondía al de la misión de San Ignacio, ubicada cerca del paralelo $28^{\circ}$ (Figura 3).

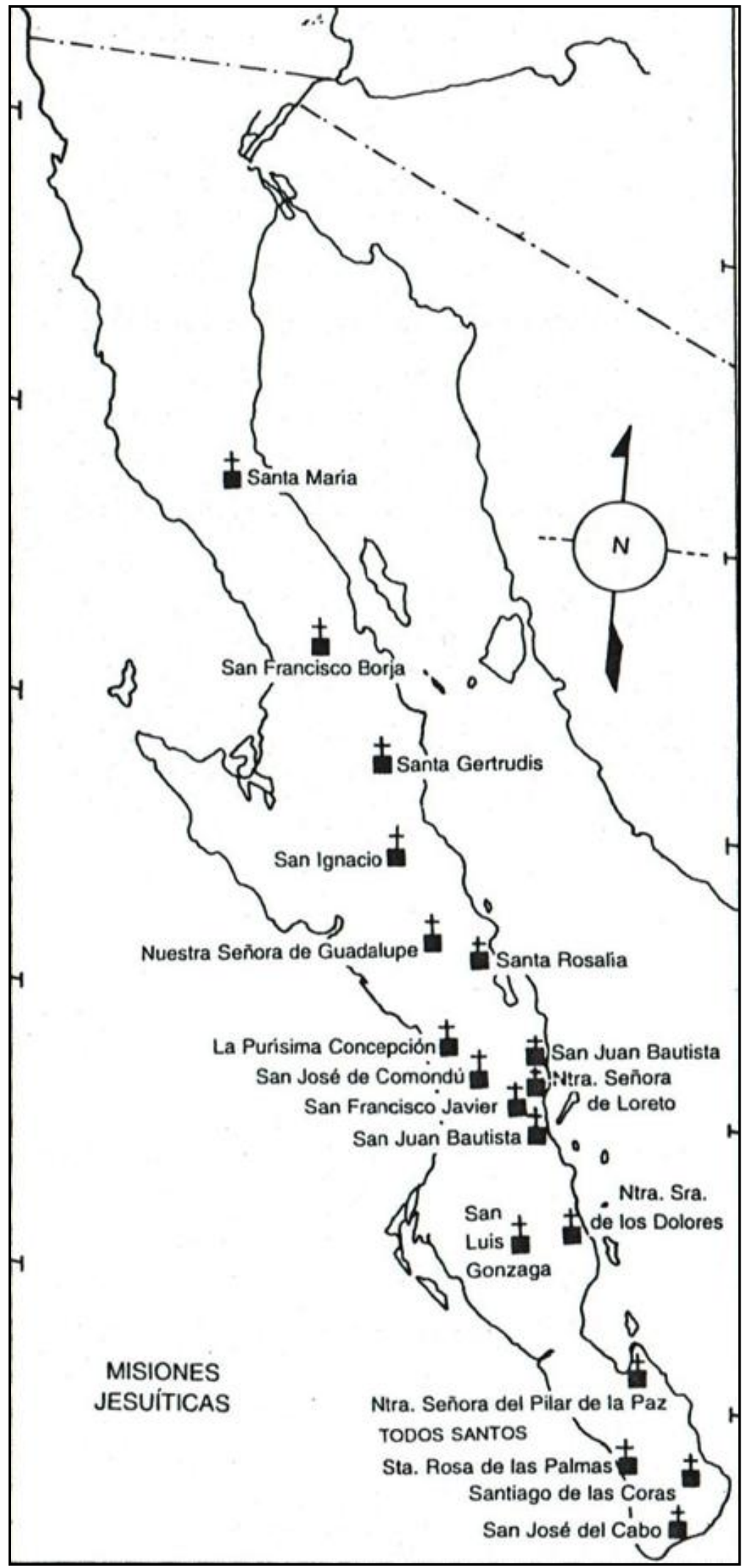

Fig. 3 Establecimiento del sistema misional jesuita en la península de Baja California (1697-1768) (Messmacher, 1997). 
Fue hasta 1753 cuando el padre Fernando Consag, durante sus viajes de exploración por las costas del golfo de California, encontró el límite de la lengua cochimí al norte, cerca del actual poblado de San Felipe (Mixco, 2010, p. 25). Mientras que el padre Wenceslao Linck, durante las exploraciones que realizó al centro de la península en el año 1766, encontró el límite de esta lengua en las estribaciones al sur de la sierra de San Pedro Mártir, no hallando rasgos de esta más al norte de este lugar (Del Barco, 1973).

Fueron los cochimí los pobladores del desierto central bajacaliforniano, estos grupos se dispersaban por un territorio más amplio en comparación con los grupos hablantes del pericú o guaycura. Durante el siglo XVIII, los cochimí se encontraban sobre aproximadamente 400 millas al centro de la península de Baja California (Aschmann, 1959; Golla, 2011; Massey, 1949; Mixco, 1978) y debido al amplio territorio en el que habitaban se propició la diversificación de diferentes dialectos de esta lengua. La misión de San Borja fue el centro de diversificación (Mixco, 1978, 2010) y para poder diferenciar entre todos los dialectos que se hablaban en la región ocupada por estos grupos, los misioneros jesuitas los agruparon en dos ramas: el cochimí del norte y cochimí del sur. Ambas ramas se diferenciaban una de otra por que correspondían con el asentamiento misional al cual se encontraban mas cercanos los grupos; de manera que se señalaba al cochimí del norte (borjeño) como correspondiente a las misiones de San Borja, Santa Gertrudis, Santa María, San Fernando Velicatá y a la misión de Nuestra Señora del Rosario, mientras que la rama sur (ignacieño y cadegomeño) se encontraba en el territorio comprendido entre la misión de San Ignacio y la misión de San Javier (Golla, 2011).

\section{Algunos documentos jesuitas escritos durante el siglo XVIII}

Una de las obras más amplias que se conocen actualmente sobre la etnología, la botánica, la minería y ciertas crónicas sobre el pasado de Baja California es la que escribió el padre de origen español Miguel Del Barco en la década de 1770, bajo el título Correcciones y adiciones a la Historia o Noticia de la California en su primera edición en Madrid, año de 1757. Con esta obra Del Barco tenía el propósito de complementar la información proporcionada por Miguel Venegas ${ }^{2}$ sobre temas generales de la península (León-Portilla, 2000), pues carecía de contenido debido a que Venegas nunca estuvo en la península de Baja California.

Aún y con las aportaciones del padre Del Barco a la obra de Venegas, se puede considerar a la obra de Del Barco como independiente, ya que está elaborada a partir de la experiencia personal de él en tierras peninsulares, y a diferencia de Venegas y Buriel, Del Barco sí habitó en la Antigua California por casi treinta años, donde llegó a ser visitador, el cargo más importante de las misiones en California (Varela, 2016). En la península, Del Barco fundó y construyó la misión de San Francisco Javier, a 35 kilómetros al sur de Loreto, considerada una de las misiones hasta ahora mejor conservadas

\footnotetext{
${ }^{2}$ La obra de M. Venegas fue titulada Empressas apostólicas de los padres misioneros de la Compañía de Jesús, de la Provincia de la Nueva España, obradas en la conquista de California... esta fue escrita con base en cartas, diarios e informes que los misioneros jesuitas de la península le hacían llegar en México para poder elaborar un informe general sobre las tareas misionales de la Compañía en tierras peninsulares. Posteriormente este título fue modificado por Andrés Marcos Buriel -editor de la obra de Venegas en España- para su impresión en Madrid en 1757 por el de Noticias de la California y su Conquista temporal y espiritual hasta el tiempo presente...
} 
por su construcción de cantera y donde desde su llegada comenzó a aprender la lengua cochimí de la región, en la cual permaneció hasta el momento del destierro de la Compañía de Jesús en 1768 de las colonias españolas (Gonzáles \& Anzures, 2015, p. 179). En 1973 Miguel León-Portilla editó la obra del padre Del Barco y fue publicada por la Universidad Nacional Autónoma de México bajo el título Historia Natural y Crónica de la Antigua California.

Otra de las obras tomadas en cuenta en este estudio es la del padre de origen alemán Juan Jacobo Baegert, titulada Noticias de la Península Americana de California, con un doble apéndice sobre falsas informaciones, publicada en 1771 (Gonzáles \& Anzures, 2015; León-Portilla, 2000; Varela, 2016). El padre Baegert habitó en la misión de San Luis Gonzaga durante casi 17 años, hasta su expulsión de la península en 1768, esta región era habitada por grupos de lengua guaycura, los cuales, a pesar de que eran grupos lingüísticamente diferentes a los cochimí, eran culturalmente semejantes (Mathes, 1980, p. 31). Paul Kirchhoff, en el prologo que hizo a la edición en español de esta obra, considera que la misión de San Luis Gonzaga era la más aislada de todas, pues se encontraba fuera de las rutas que conectaban a las misiones más importantes (Kirchhoff, 2013).

La obra de Baegert es una de las que más pasiones y polémicas ha desatado dentro de los estudios históricos de la península, ya que en ella describe con atención la pobreza y carencias que sufrían los indios y misioneros en la Antigua California. Esto se ha interpretado como una respuesta del propio Baegert a la edición francesa de la obra de Venegas, la cual en su momento alimentó con falsas ideas a los que consideraba eran los enemigos de los jesuitas en España sobre supuestas riquezas en la Antigua California (León-Portilla, 2000, p. 199). La primera edición de esta obra en español fue publicada en 1942; la edición más reciente de esta obra fue editada por Elizabeth Acosta en el año 2013 y publicada por el Archivo Histórico Pablo L. Martínez, de la ciudad de La Paz, Baja California Sur, México.

Otra de las fuentes consultadas para realizar este trabajo fue la del mexicano Francisco Xavier Clavijero, quien ingresó a la Compañía de Jesús en 1748 y sobresalió como profesor, filósofo e historiador. Clavijero escribió su obra en italiano -durante su exilio en Italia-, fue publicada dos años después de su muerte, en 1789, bajo el título Historia de la California. Aunque Clavijero nunca estuvo en la península de Baja California pudo conocer a algunos misioneros que sí habían estado ahí, con quienes intercambio información y reunió documentos referentes a las noticias de la península (León-Portilla, 2007). Conoció las obras de Venegas y de Baegert, aunque nunca pudo consultar la obra de Baegert, sí pudo notar, al igual que Del Barco, ciertas carencias y errores en el trabajo de Venegas (León-Portilla, 2007). Por lo que interesado en la historia indígena de México y en especial de la California jesuita, se dio a la tarea de elaborar un manuscrito que reuniera la información generada por los jesuitas antes de su expulsión de la península utilizando textos de los padres Del Barco y Lucas Ventura (LeónPortilla, 2007).

En su obra se presenta un resumen sobre la visión etnológica que tenían los jesuitas de las culturas de la Antigua California, los diversos intentos de colonización de la península, ocurridos desde el siglo XVI por Hernán Cortes hasta las realizadas en el siglo XVIII por el establecimiento del sistema misional jesuita, las fundaciones que realizó la Compañía de Jesús en la tierra peninsular y la posibilidad en aquella época de explorar más al norte de los establecimientos jesuitas, gracias a la fundación y exploración de nuevos territorios por estos. La primera edición traducida al español de la obra 
de Clavijero se publicó en México en 1852, posteriormente en 1933, se volvió a editar la obra de Clavijero en español y en 1970, Miguel León-Portilla la editó con el título Historia de la Antigua o Baja California, constando hasta el momento con cinco reediciones.

\section{Las poblaciones seminómadas de la península de Baja California}

Las poblaciones humanas que habitaron en la península de Baja California antes de la llegada de los jesuitas fueron cazadores-recolectores-pescadores seminómadas que se agrupaban en pequeños grupos compuestos por alrededor de entre veinte y cincuenta individuos, emparentados por familias consanguíneas que se asentaban alrededor de distintos aguajes para explotar recursos vegetales, animales o minerales como forma de subsistencia (Aschmann, 1959; Bendímez, 1985; Fujita, 2010; Gutiérrez \& Hyland, 2006; Massey, 1949). A esta forma de organización se les ha denominado desde la perspectiva antropológica como: bandas. Las cuales se diferencian de otras formas de organización social como los poblados, pues la forma de vida de las bandas es completamente migratoria en torno a los alimentos que puedan obtener durante distintas épocas al año (Harris, 2011).

La conformación familiar de los grupos peninsulares estaba organizada bajo un sistema patrilineal exogámico (Uriarte, 2013, p. 43), descrito por el padre Baegert de la siguiente manera: "mientras existía entre ellos la poligamia, acostumbraban casarse con todas las hermanas, si había varias en una familia"3. Esta forma de organización, además de conservar a las mujeres dentro de un grupo, les permitía a los bajacalifornianos intercambiar hombres y mujeres mediante acuerdos matrimoniales, de manera que las parejas se unían a la banda del hombre y era en esta unidad donde crecían los hijos de ambos (Uriarte, 2013, p. 44). Aunque recientemente se ha planteado que la poligamia entre los grupos al sur de la península fue una estrategia para conservar y garantizar la reproducción biológica y social de los grupos de esa región debido a la acelerada tasa de defunciones que comenzaron a sufrir con la llegada de los europeos (Rosales-Lopéz \& Fujita, 2000, p. 27).

La costumbre de intercambiar hombres y mujeres entre los distintos grupos permitía que se formaran y reforzaran alianzas entre ellos, lo cual era benéfico para uno u otro grupo al momento de entrar en guerra en contra de otro y durante la recolección de alimentos o caza de animales, pues las alianzas le permitían a estos grupos acceder a los territorios explotados por otros durante las temporadas de escasez de alimentos.

Los jesuitas no observaron la existencia de formas de autoridad o de gobierno entre los grupos bajacalifornianos, únicamente llegaban a sobresalir los mejores cazadores y los hombres más valientes, a los cuales se les daba la oportunidad de indicar las direcciones hacía donde se desplazaría el campamento en búsqueda de alimentos y de dirigir las tareas de pesca o caza (Clavijero, 2007, p. 60). Sobre el sistema de creencias de estos grupos se sabe que existía una persona que tenía un papel simbólico dentro de las ceremonias, similar a la figura de chamán para la antropología contemporánea, es decir, especialistas mágico-religiosos de tiempo parcial que intervienen en la opinión pública y evitan la generación de conflictos dentro de una sociedad (Harris, 2011, p. 278). Estos especialistas eran llamados por los cochimí guama, eran los encargados de realizar las tareas de curanderos, adivinos (Del Barco, 1973) y de enseñar los dogmas a

\footnotetext{
${ }^{3}$ Baegert, 2013, p. 121.
} 
los niños, eligiendo a los que podrían ser más capaces para llevar a cabo las tareas de este oficio por su astucia o aptitudes como lo describe Clavijero:

“... y llevándolos a los lugares más recónditos de los bosques, los iban adiestrando en sus misterios, y especialmente en hacer en ciertas tablitas algunas figuras misteriosas, que fingían ser copias de las que, según decían, les había dejado al retirarse el espíritu visitador. Estas tablitas eran los libros en que fingían leer la naturaleza de las enfermedades, los remedios a ellas convenientes, las futuras mutaciones del aire y aun el destino de los hombres"

Estos grupos vivían en un sistema igualitario, en donde ningún individuo tenía más posesiones que otro (Baegert, 2013, p. 125), por este motivo los jesuitas notaron que entre los individuos de cada grupo no se hurtaban cosas unos a otros, debido a que tenían pocas cosas y razón por la cual las riñas entre familiares o personas de una misma banda eran inexistentes, siendo las guerras o luchas únicamente en contra de otros grupos, con los que estaban enemistados (Clavijero, 2007, p. 52).

Respecto a las formas de regular el número de individuos dentro de una banda o grupo, se sabe que eran pocas las mujeres que lograban tener hijos, esta condición les permitía a los bajacalifornianos mantener una densidad de población baja, lo cual fue benéfico ante las condiciones de aridez y poca abundancia de los recursos de subsistencia como el agua y los alimentos. Las fuentes jesuitas también señalan que las mujeres que habían tenido ocho o más veces hijos, solo uno o dos de estos lograba sobrevivir (Baegert, 2013, p. 100). En otros casos se describen situaciones en las cuales algunas mujeres abortaban a su primer hijo, pues se pensaba que sería enfermizo y débil (Clavijero, 2007, p. 62).

$\mathrm{Al}$ parecer las poblaciones bajacalifornianas anteriores al establecimiento del sistema misional del siglo XVIII pusieron en práctica controles demográficos enfocados en la reducción de su población mediante el suicidio de infantes o el aborto de las mujeres embarazadas, fenómeno social visto y descrito por el padre Miguel del Barco de la siguiente manera: "el amor a los hijuelos no era tanto que impidiese matar algunas veces a sus criaturas cuando no les alcanzaba el sustento",

Los grupos seminómadas de la península de Baja California solían asentar sus campamentos habitacionales cerca de fuentes de agua dulce, como arroyos de temporada, estuarios, lagunas, manantiales y tinajas (Fujita, 2010, p. 112). La movilidad y unión de estos grupos estuvo fuertemente influencia por el ambiente y los recursos vegetales que podían encontrar en el medio, de manera que cuando eran abundantes las plantas, frutos, semillas y raíces comestibles varios grupos podían permanecer juntos en un mismo campamento, mientras que cuando había escasez de estos alimentos los grupos se dispersaban y podían volver a juntarse después, cuando volvieran a ser abundantes (Baegert, 2013, p. 125; Del Barco, 1973, p. 188).

\section{La estacionalidad de los alimentos y su recolecta}

Hace cerca de 7,000 años en la región que ahora comprende al desierto central de la península de Baja California comenzaron a ocurrir cambios climáticos que provocaron el aumento de la temperatura, iniciando el proceso de desecación que puede ob-

\footnotetext{
${ }^{4}$ Clavijero, 2007, p. 67.

${ }^{5}$ Del Barco, 1973, p. 191.
} 
servarse hasta la época actual (Davis, 2003). Este cambio climático modificó la distribución y el tipo de vegetación con la que se alimentaban los grupos prehistóricos y las demás especies animales, sin embargo esto no significó la falta de alimento para estos grupos, pues su dieta comenzó a basarse en el consumo de alimentos de origen animal de tallas menores como los roedores, las serpientes, los insectos, los murciélagos y en menor medida, el borrego cimarrón y el venado bura, vegetales, pescados y moluscos (Del Barco, 1973).

Gracias a los testimonios del padre Baegert se sabe que los alimentos de origen animal no se consumían diariamente (Baegert, 2013, p. 94), quizá por las implicaciones de desgaste energético que la cacería de animales implicaba, pues hay que recordar que subsistían en un medio donde había escasez de agua. En cambio, cerca del $85 \%$ de la alimentación de los cochimí estaba conformada por una dieta basada en la recolección de vegetales comestibles, frutos, raíces y semillas hacía el final del periodo prehistórico (Aschmann, 1959; Gutiérrez \& Hyland, 2006), que inicia hace 1,500 años (Laylander, 1987, p. 120) y comienzo del periodo misional (Siglo XVIII).

La recolección de los alimentos vegetales implicó para los grupos seminómadas de Baja California la movilización de sus campamentos a través de distintos nichos ecológicos de manera cíclica-anual en búsqueda de los frutos, las semillas y las plantas que les fueran útiles para alimentarse, los jesuitas fueron testigo de este proceso de movilidad relacionado con la recolección de recursos vegetales, también señalaron que el calendario de movilidad de los cochimí contaba con seis estaciones, en las cuales se recolectaban diferentes especies vegetales (Clavijero, 2007).

\section{Calendario de recolección vegetal}

La estación que marcaba el inicio del ciclo anual de recolección para los cochimí era llamada mejibó, esta abarcaba los meses de junio, julio y parte de agosto. El inicio de esta estación marcaba el transcurso de un año y era de gran importancia para estos grupos ya que era la época en que disponían de una gran abundancia de frutos y semillas (Clavijero, 2007), como las semillas localizadas al interior de las vainas del árbol palo verde (Parkinsonia microphylla [Cercidium microphyllum]), que era llamado por los cochimí medesá (Clavijero, 2007, p. 22; Del Barco, 1973, p. 68) y se recolección se realizaba durante el mes de julio. Las semillas las tostaban y posteriormente las molían, transformándolas en harinas que servían como alimento durante las estaciones consideradas como el invierno (Del Barco, 1973, p. 67-68).

Otros alimentos que los cochimí recolectaban durante la estación mejibó fueron los frutos y las semillas de diversas especies de la familia de las cactáceas, las cuales conforman la mayoría de la flora del desierto central de Baja California y los recolectaban a partir de junio, mes en que comienzan a madurar. Entre los frutos que recolectaban se encuentran los de cardones (Pachycereus pringlei), de los cuales extraían sus semillas, pues eran muy estimadas debido a su sabor. Luego las tostaban y las transformaban en harinas, para conservarlas como fuente de alimento durante la temporada invernal (Clavijero, 2007, p. 20; Del Barco, 1973, p. 83).

Otro de los frutos que recolectaban los cochimí durante la estación mejibó fueron los de las biznagas (Ferocactus gracilis var. gracilis), de los cuales obtenían sus semillas abriéndolos y dejándolos secar al sol, para que la pulpa del fruto desapareciera por desecación. Al momento en que el fruto se consumía por completo, recolectaban sus 
semillas, las tostaban y las guardaban para también poder comerlas molidas durante las temporadas de escasez de alimentos (Clavijero, 2007, p. 20; Del Barco, 1973, p. 87). La semilla del fruto del garambullo (Lophocereus schottii var. Schottii) también era apreciada por estos grupos, a estos frutos los cochimí le llamaban gkakil o gakil $^{6}$ y preferían recolectarlos antes que a los otros frutos, ya que los frutos del garambullo duran pocos días maduros y tenían que recolectar sus semillas antes de que cayeran al suelo. Posteriormente las tostaban para que no se pudrieran y para que más adelante los transformaran en harina y sirviera como alimento durante las estaciones de escasez de alimentos (Clavijero, 2007, p. 19; Del Barco, 1973, p. 82).

Resulta interesante la atención que se pone en las fuentes jesuitas al fruto de las pitahayas, pues en las tres obras consultadas y al parecer en la mayoría de los informes jesuitas se menciona que estos frutos eran los de mayor importancia para los cochimí ya que era un alimento que podían obtener en gran abundancia durante la estación mejibó (Baegert, 2013; Del Barco, 1973). Los frutos de las pitahayas pueden dividirse en dos especies: una dulce y otra agria, la recolección de cada una de estas se realizaba en diferentes estaciones. Durante mejibó se recolectaba la pitahaya dulce (Stenocereus thurberi var. thurberi), los cochimí le llamaban a esta especie tammiá o dammiá (Clavijero, 2007, p. 18), la temporada de recolección en el desierto central comenzaba en agosto, mientras los grupos de sur de la península la recolectaban a partir de mediados de junio y hasta finales de agosto (Clavijero, 2007; Del Barco, 1973). Esto muestra algunas diferencias en la oferta estacional de alimentos en las distintas regiones de la península de Baja California.

La recolección de los frutos de las cactáceas implicó una intensa movilidad de los bajacalifornianos sobre las mesas, los barrancos de las sierras y las laderas de las cañadas, formas geográficas que favorecen el crecimiento de este tipo de vegetación (Gutiérrez \& Hyland, 2006, p. 88). En su recolección participaban los hombres y las mujeres de cada grupo, los cuales salían de sus campamentos armados con un gancho que les servía para desprenderlos, así como de una red con la que transportaban y limpiaban los frutos de sus espinas, no sin antes saciarse primero ellos mismos de los frutos que podían conseguir durante la jornada de recolección (Clavijero, 2007, p. 19; Del Barco, 1973, p. 79).

Pero no solamente era el fruto de las pitahayas los que gozaban de tal importancia, sus semillas también fueron muy importantes dentro de la dieta de los bajacalifornianos, tanto que su forma de recolección llamó la atención de los jesuitas debido a la manera en que solían hacerlo:

"En tiempo de pitahayas, en que regularmente no comían otra cosa, cada familia prevenía un sitio cerca de su habitación en que iban a deponer la pitahaya después de digerirla según orden natural; y para mayor limpieza ponían en aquel sitio piedras llanas o yerbas largas y secas o cosa semejante, en que hacer la deposición sin que se mezclase con tierra o con arena. Después bien seca, la echaban en las bateas las mujeres, desmenuznádola allí con las manos hasta reducir a polvo todo lo superfluo y que no era semilla de pitahayas: sin que esta operación les causase más fastidio que si anduvieran sus manos entre flores. Para apartar

\footnotetext{
${ }^{6}$ El nombre de los frutos en la lengua cochimí se encuentra escrito de distintas formas dentro de las fuentes jesuitas, en este caso gkakil es mencionado por el padre Francisco Clavijero (2007), mientras que el padre Miguel del Barco (1973) los menciona como gakil.
} 
aquel fétido polvo de la semilla, movían la batea como se hace cuando se limpia cualquiera grano." 7

A esta forma de obtener las semillas de las pitahayas los jesuitas le llamaron la segunda $\operatorname{cosech}^{8}$, y al igual que al resto de las semillas recolectadas de otros frutos, con las semillas de la pitahaya preparaban harina, que era su alimento durante la temporada invernal (Clavijero, 2007, p. 54; Del Barco, 1973, p. 205).

Como ya se dijo, la estación mejibó fue la más importante para la subsistencia de los grupos baja californianos debido a la abundancia de frutos y semillas que podían conseguir los grupos bajacalifornianos, esto permitió que varios grupos se reunieran en un mismo territorio, lo cual permitía también la reproducción de la vida social o pública de cada grupo. Al respecto, los jesuitas mencionan que esta estación representaba una época de festejos y bailes que permitía la convivencia en un mismo territorio de dos o más grupos, pues podían compartir los frutos de la pitahaya (Baegert, 2013; Clavijero, 2007; Del Barco, 1973).

Clavijero señala que era tanta la importancia de este alimento durante la estación mejibó que los cochimí celebraban matrimonios de sus familiares durante esta estación y programaban el nacimiento de los niños para esta estación, también se realizaban ceremonias en conjunto para pedir el éxito en las tareas de cacería, pesca y recolección de alimentos, así como alcanzar la victoria en contra de sus enemigos si se enfrentaban contra algún grupo rival (Clavijero, 2007, p. 60).

La segunda estación del calendario cochimí era la que llamaban amadá - appí (Clavijero, 2007). Esta iniciaba a mediados de agosto y comprendía los meses de septiembre y parte de octubre, durante esta estación los cochimí también llegaban a sentir gran regocijo debido a que la vegetación comienza a reverdecer y los depósitos de agua se renuevan (Baegert, 2013). Esta estación coincide con la época de lluvias en la península de Baja California, durante la cual pueden llegar a formarse huracanes sobre el océano Pacífico que llegan a impactar con la península, intensificando las precipitaciones pluviales.

Durante la estación amadá - appí los cochimí continuaban recolectando frutos de los vegetales pertenecientes a la familia cactácea, como el caso de las tunas (Opuntia), a las cuales les llamaban simplemente $a$, y podían encontrarlas maduras durante el mes de septiembre (Del Barco, 1973, p. 89). Otro de los frutos que recolectaban durante esta estación eran los de la pitahaya agria (Stenocereus gummosus), su recolección era de manera similar a la descrita para el caso de la pitahaya dulce. A estos frutos los cochimí le llamaban tajuá o fajuá ${ }^{9}$ y su recolección iniciaba un poco antes de septiembre y continuaba hasta octubre (Clavijero, 2007; Del Barco, 1973). En algunas ocasiones, cuando existía abundancia de estos frutos por el incremento de las precipitaciones, se podían recolectar hasta el mes de noviembre (Baegert, 2013, p. 45; Clavijero, 2007, p. 19; Del Barco, 1973, p. 81).

\footnotetext{
${ }^{7}$ Del Barco, 1973, p. 205

${ }^{8}$ Esta descripción que hace el padre del Barco resulta de gran importancia etnológica para el estudio de las formas de vida de los antiguos pobladores de la península de Baja California, pues brinda un panorama sobre las precariedades en las que subsistían estas poblaciones.

${ }^{9}$ Depende la fuente que se consulte, pues el padre Clavijero (2007) los llama tajúa y el padre Del Barco (1973) los llama fajúa.
} 
La abundancia de los frutos de la pitahaya influía fuertemente sobre las estrategias de movilidad y asentamiento de los campamentos habitacionales, ya que a diferencia de los frutos de la pitahaya dulce, que se recolectaban en las sierras y valles al interior de la península, los frutos de la pitahaya agria se recolectaban en los valles cercanos a las costas del golfo de California o del océano Pacífico, ya que pocas veces podían encontrarlos en las serranías al interior de la península (Clavijero, 2007, p. 19; Del Barco, 1973, p. 82).

Esto implica que los grupos seminómadas de la península de Baja California debían desplazarse del centro de la península hacía las costas para obtener los frutos de pitahaya agria. Por lo tanto, de manera preliminar se puede inferir que estos grupos podían permanecer juntos en un mismo territorio durante la estación mejibó y comenzaban a dispersarse hacía las planicies costeras de ambos mares que rodean a la península al iniciar la estación amadá - appí; esto quizá implicó también el incremento de consumo de alimentos de origen marino como crustáceos, moluscos, pescados y mamíferos marinos durante la estación amadá - appí, en la cual también comenzaban a almacenar los alimentos (harinas) que habían procesado durante esta y la estación anterior (mejibó) (Baegert, 2013, p. 19). Durante esta estación no solo las pitahayas fueron de valor por su fruto o semillas, estas también otorgaban a los grupos prehistóricos cierto porcentaje de agua, recurso del cual podían prescindir durante varios días consumiendo únicamente frutos de pitahaya (Baegert, 2013, p. 25), por lo tanto se consideraba al de la pitahaya agria, un alimento y una fuente de agua debido a su gran cantidad de jugo (Del Barco, 1973, p. 81).

La tercera estación del ciclo de movilidad de los cochimí era llamada amadá appigala (Clavijero, 2007). Esta estación abarcaba los meses de octubre, noviembre y parte de diciembre, meses en los cuales la vegetación que había crecido en la temporada anterior comenzaba a secarse y ser escasa (Clavijero, 2007, p. 51). Durante esta estación los cochimí también subsistían recolectando, tostando y transformando en harinas las semillas de arbustos como el llamado corallita (Antigonon leptopus), al que llamaban teddá (Clavijero, 2007, p. 22; Del Barco, 1973, p. 106).

Otro de los arbustos de los que recolectaban sus semillas era el llamado ortiga (Urtica dioica subsp. holosericea), durante el mes de octubre y al cual le llamaban tedeguá, que en lengua cochimí significaba "lo que causa dolor", ya que si una de sus espinas llegaba a picar a quien lo manipulaba le causaba dolor en la región donde se incrustaba la espina (Del Barco, 1973, p. 107). Otro de los recursos vegetales con los cuales subsistían durante la estación amadá - appigala eran las semillas de las verdolagas (Trianthema portulacastrum), las cuales se consumían crudas (Del Barco, 1973, p. 106).

La cuarta estación del ciclo de movilidad en torno a los alimentos vegetales comprendía los meses más fríos. Iniciaba en diciembre, comprendía enero y febrero, a esta estación los cochimí le llamaban majibél y era durante la cual los agaves cobraban gran importancia para la subsistencia de los grupos seminómadas de la península de Baja California (Clavijero, 2007). Aunque los agaves se encuentran disponibles la mayor parte del año, los bajacalifornianos preferían no consumirlos durante las tres estaciones anteriormente señaladas pues contaban con otros alimentos durante esas estaciones (Del Barco, 1973, p. 121).

El consumo de los agaves iniciaba a partir de octubre y continuaba hasta abril (Clavijero, 2007, p. 29), era el principal alimento durante las estaciones de invierno, en las que los vegetales pueden llegar a ser escasos. En la península de Baja California 
existen alrededor de 20 especies de agaves (Rebman \& Roberts, 2012, p. 67), sin embargo no todas eran consumidas por los cochimí. La recolección de estos vegetales implicaba durante la mayoría de veces la movilización de todo el grupo junto con el resto de sus campamentos, debido a que las colonias de estos vegetales se podían encontrar lejos de las fuentes de agua (Baegert, 2013, p. 90). Su recolección era tarea de las mujeres, quienes hacían tal labor en las sierras al interior de la península, ya que estos no se encuentran en las playas, por lo que si alguno de los grupos que habitaban en las playas quería o necesitaba alimentarse con este vegetal, tenía que acceder a las sierras del interior de la península para poder obtenerlo (Del Barco, 1973, p. 124).

Durante la recolección de los agaves participaban tres o cuatro mujeres de un solo grupo, utilizaban un cuchillo de piedra con que cortaban las pencas hasta dejar únicamente la piña de estos, cada mujer lograba recolectar cerca de ocho o nueve piñas de agave, que transportaban en redes hechas con fibras de esos mismos vegetales hacía sus campamentos (Del Barco, 1973, p. 123), cerca de los cuales construían un horno de acuerdo al siguiente procedimiento: primero se hacía un hoyo en el suelo, en que prendían lumbre y metían algunas piedras, cuando la leña se consumía y las piedras estaban calientes ponían entre ellas los trozos de agave, los cubrían con tierra y los dejaban ahí asándose durante 12 ó 14 horas según Baegert (2013, p. 94) o hasta 24, 30 o 36 horas según Clavijero (2007, p. 29). La finalidad de asar las piñas era obtener de ellas un sabor dulce y ablandarlas. Esta forma de preparación le permitía a los bajacalifornianos alimentar a un solo grupo por alrededor de tres días; mientras que las piñas que no se consumían, se dejaban secar, para hacer con ellas harina, con la cual alimentaban a los ancianos (Baegert, 2013; Clavijero, 2007; Del Barco, 1973).

La quinta estación del ciclo de movilidad de los cochimí era la que llamaban majiben (Clavijero, 2007), esta comprendía los meses de febrero, marzo y parte de abril. Para los cochimí del norte los agaves seguían siendo el principal recurso alimenticio durante esta estación, sin embargo, las fuentes jesuitas señalan que durante esta estación los grupos del sur comenzaban a complementar su dieta con la recolección y consumo de los frutos de un árbol que llamaban guigil (probablemente Castela peninsularis), que madura entre los meses de marzo o abril (Del Barco, 1973, p. 99).

Otro de los alimentos vegetales que los cochimí que habitaban al interior de la península aprovechaban durante esta estación eran las raíces de la yuca, a las cuales le llamaban ujuí o $u f u{ }^{10}{ }^{10}$. Este tipo de vegetales pertenecen a la familia de las cactáceas y en la península de Baja California es posible encontrar dos especies endémicas: Yucca schidigera y Yucca valida. Ambas especies son conocidas como datilillo (Rebman \& Roberts, 2012, p. 75) y los bajacalifornianos consumían las raíces de estos vegetales cuando tenían buen tamaño. Su forma de obtención era haciendo un hoyo al pie de la planta y con un palo las extraían, posteriormente las asaban y se comían (Del Barco, 1973, p. 125).

La última estación del ciclo anual de aprovechamiento de recursos de los cochimí era la que llamaban majiiben - maají, que correspondía a los meses de abril, mayo y parte de junio. Esta estación era considerada como la de mayor escases de alimentos o el invierno, pues durante esta estación los últimos vegetales que permitían su subsistencia comenzaban a agotarse o a secarse (Del Barco, 1973, p. 125; Martínez, 2011, p. 39). Era en esta estación en la cual los cochimí y demás grupos bajacalifornianos se

\footnotetext{
${ }^{10}$ El nombre depende la fuente que se consulte, el padre M. Del Barco (1973) los llama ujuí y el padre F. Clavijero (2007) los llama ufuí.
} 
alimentaban con la harina de las semillas que habían recolectado, tostado y molido en durante las dos primeras estaciones. De manera que las provisiones de alimento que lograban reunir a lo largo del año les permitían subsistir por algunas semanas hasta que volviera a iniciar la estación del mejibó, cumpliendo de esta manera su agenda económica marcada por la estacionalidad de los recursos vegetales.

Aunque los cochimí se alimentaban durante la última estación de sus ciclo anual con las provisiones que habían conservado durante el año, podían complementar su ingesta de alimentos vegetales con semillas de palo chino (Acacia greggi), cuyos frutos brotan durante la estación majiiben - maají y a los cuales les llamaban agigandú (Del Barco, 1973, p. 71). Otro de los escasos alimentos vegetales con los se alimentaban durante esta eran unos frutos que los padres jesuitas asemejaban con los higos europeos y que obtenían de un árbol llamado Salate (Ficus palmeri), al que los cochimí llamaban anabá y que recolectaban y consumían hasta saciarse, el resto de los frutos recolectados en una jornada los cargaban en una red para transportarlos a sus campamentos y poder alimentar al resto del grupo (Del Barco, 1973, p. 66).

\section{La construcción de un modelo de movilidad en el desierto central de Baja Califor- nia durante la prehistoria tardía}

Así es como se muestra un panorama general sobre como los grupos seminómadas que habitaban en la península de Baja California al momento de la llegada de los misioneros jesuitas lograban subsistir a lo largo del año, recolectando diversos vegetales y explotando diferentes nichos ecológicos como los valles, las sierras o las costas de manera estacional sucesiva. El énfasis que se ha puesto en explicar la importancia de los alimentos vegetales fue direccionado en explicar la manera en que su recolección influía en gran medida sobre la movilidad estacional de los grupos seminómadas y la manera en que las fuentes jesuitas del siglo XVIII ayudan a entender esos procesos.

Esto no quiere decir que los alimentos de origen animal terrestres o marinos no fueran aprovechados como fuentes de alimento durante las estaciones mencionadas, simplemente como se mencionó más arriba, los alimentos de origen animal no representaban para estos grupos la cantidad necesaria de beneficios energéticos suficientes para poder alimentar a uno o varios grupos, salvo en momentos excepcionales como lo pudo ser la caza de un venado o un borrego cimarrón, animales que por su tamaño podrían aportar gran cantidad de recurso energético.

Como se ha visto en el desarrollo de este texto, con el estudio de algunas de las fuentes históricas legadas por los misioneros jesuitas que habitaron en la península de Baja California, es posible construir un modelo idealizado sobre el ciclo de recolección y la movilidad estacional de los cochimí en torno a diferentes especies vegetales comestibles (Cuadro 1). Este se plantea que pudo ser similar en el periodo anterior al establecimiento del sistema misional jesuita en la península de Baja California, el cual sufrió cambios durante la instalación de este sistema, pues se modificaron las pautas alimenticias y dinámicas de obtención de alimento de los grupos nativos, ingresando a su dieta cereales y otros alimentos de origen foráneo. 


\begin{tabular}{|c|c|c|c|}
\hline $\begin{array}{l}\text { Estación } \\
\text { de reco- } \\
\text { lección }\end{array}$ & Nombre común & Nombre científico & cochimí \\
\hline \multirow{5}{*}{$\begin{array}{l}\text { mejibó } \\
\text { (junio, } \\
\text { julio, } \\
\text { agosto) }\end{array}$} & Palo verde & $\begin{array}{l}\text { Parkinsonia microphylla [Cercidium microphy- } \\
\text { llum] }\end{array}$ & medesá \\
\hline & Cardón & Pachycereus pringlei & - \\
\hline & Biznaga & Ferocactus gracilis var. gracilis & - \\
\hline & Garambullo & Lophocereus schottii var. schottii & gkakil o gakil \\
\hline & Pitahaya dulce & Stenocereus thurberi var. thurberi & tammiá o dammiá \\
\hline \multirow[b]{2}{*}{$\begin{array}{l}\text { amadá- } \\
\text { appí } \\
\text { (agosto, } \\
\text { septiem- } \\
\text { bre, octu- } \\
\text { bre) }\end{array}$} & Tuna & Opuntia & $a$ \\
\hline & Pitahaya agria & Stenocereus gummosus & tajuá o fajuá \\
\hline \multirow{3}{*}{$\begin{array}{l}\text { amadá- } \\
\text { appigala } \\
\text { (octubre, } \\
\text { noviem- } \\
\text { bre, di- } \\
\text { ciembre) }\end{array}$} & Corallita & Antigonon leptopus & teddá \\
\hline & Ortiga & Urtica dioica subsp. holosericea & tedeguá \\
\hline & Verdolaga & Trianthema portulacastrum & - \\
\hline $\begin{array}{l}\text { majibél } \\
\text { (diciem- } \\
\text { bre, enero, } \\
\text { febrero) }\end{array}$ & Mezcales & agaves & - \\
\hline \multirow{2}{*}{$\begin{array}{l}\text { majiben } \\
\text { (febrero, } \\
\text { marzo, } \\
\text { abril) }\end{array}$} & $\begin{array}{l}\text { Espina de la cruci- } \\
\text { fixión }\end{array}$ & Castela peninsularis & guigil \\
\hline & Datilillo & Yucca schidigera о Yисса valida & ujuí o ufuí \\
\hline \multirow{2}{*}{$\begin{array}{l}\text { majiiben- } \\
\text { maaji } \\
\text { (abril, } \\
\text { mayo, } \\
\text { junio) }\end{array}$} & Palo chino & Acacia greggi & $\begin{array}{l}\text { asigandú o agi- } \\
\text { gandú }\end{array}$ \\
\hline & Salate o higo & Ficus palmeri & anabá \\
\hline
\end{tabular}

Cuadro 1. Estaciones y recursos vegetales comestibles durante cada una de ellas.

Es posible concluir que durante la estación mejibó los cochimí y demás grupos seminómadas podían encontrar gran abundancia de frutos de pitahayas dulces, cardones, garambullos y biznagas, su recolección también implicaba la obtención de semillas que podían conservarse y transformar en harinas, que servían como alimento durante las 
estaciones majiben y majiiben - maají, las que tenían menor presencia de recursos vegetales.

El almacenamiento de alimentos durante varias estaciones le permitió la subsistencia a estos grupos, principalmente en las estaciones consideradas de invierno, las semillas y su transformación en harinas para ser empleadas como alimento en las estaciones de mayor escasez permite plantear que eran grupos nómadas que practicaban formas de movilidad del tipo colector. Las sociedades colectoras, vistas desde la perspectiva de la arqueología procesual, se caracterizan por aprovechar distintos recursos naturales, ya sean vegetales o animales en diferentes territorios y temporadas, algunos de los alimentos recolectados y cazados por las sociedades que practican este sistema de movilidad pueden ser almacenados y útiles como fuentes de alimento durante las temporadas de mayor escasez de alimentos (Binford, 1980).

De acuerdo con postulados antropológicos la abundancia de recursos alimenticios que los grupos seminómadas podían obtener en ciertas temporadas y ciertos territorios pudo permitir que tuvieran la capacidad para mantener una red de circulación de bienes y productos con otros grupos, ya fuera mediante las fiestas que se realizaban durante las estaciones del año en que los recursos alimenticios eran más abundantes (Binford, 1980; Harris, 1982). Esto último se puede comparar con las ceremonias realizadas por los cochimí en torno a la estación mejibó, en la cual la abundancia de pitahayas y demás frutos de cactáceas permitía la congregación de varios grupos en un mismo territorio.

Durante las estaciones en que los recursos de las cactáceas comenzaban a ser escasos como en la estación amadá - appí, los cochimí pudieron dispersarse hacía las costas de la península para aprovechar recursos como la pitahaya agria, pues esta aparece con mayor abundancia en estas zonas. Mientras que en las estaciones amadá - appigala, majibél, majiben algunos de los grupos que aprovechaban las pitahayas agrias en las costas se desplazaban hacía las sierras centrales para aprovechar los agaves como fuente de alimento, pues hay que recordar que los agaves únicamente crecen al interior de la península.

Por último, no hay que dejar de lado que la constante movilidad de los cochimí y demás grupos seminómadas tuvo implicaciones no solo de subsistencia, sino también de la creación y conformación de espacios territoriales con significados personales y colectivos, que pueden ahora ser ajenos a nosotros, pero que expresiones como el fenómeno pictográfico de pintura rupestre y de petrograbados que son posibles de observar en varias regiones de la península de Baja California, lo han atestiguado desde hace cientos de años.

\section{Referencias bibliográficas}

Aschmann, H. (1959). The Central Desert of Baja California: Demography and Ecology. Berkeley: University of California.

Baegert, J. (2013). Noticias de la Península Americana de California. (E. Acosta, Ed.). La Paz, B. C. S.: Archivo Histórico Pablo L. Martínez.

Bendímez, J. (1985). Algunas Consideraciones sobre la Arqueología de Baja California. Meyibó, II(5), 77-88.

Binford, L. (1980). Willow Smoke and Dogs ' Tails: Hunter-Gatherer Settlement 
Systems and Archaeological Site Formation. American Antiquity, 45(1), 4-20.

Clavijero, F. (2007). Historia de la Antigua o Baja California. (M. Portilla, Ed.). Porrúa.

Davis, L. (2003). Geoarchaeology and Geochronology of Pluvial Lake Chapala, Baja California, Mexico. Geoarchaeology. An International Journal, 18, 205-223.

Del Barco, M. (1973). Historia Natural y Crónica de la Antigua California. (M. Portilla, Ed.). Ciudad de México: Universidad Nacional Autónoma de México. Instituto de Investigaciones Históricas.

Del Río, I. (1998). Conquista y aculturación en la California Jesuítica (Serie Novo). Universidad Nacional Autonóma de México.

Del Río, I. (2000). Crónicas Jesuíticas de la Antigua California. Universidad Nacional Autónoma de México.

Fujita, H. (2010). Región del Cabo. In D. Laylander, J. Moore, \& J. Bendímez (Eds.), La Prehistoria de Baja California. Avances en la arqueología de la Península Olvidada. (pp. 103-122). Mexicali: Instituto Nacional de Antropología e Historia.

Golla, V. (2011). California Indian Languajes. University of California Press.

Gonzáles, L., \& Anzures, M. del C. (2015). Tirsch, Ignacio, 1733-1781. Pinturas de la Antigua California y de México. Códice Klementinum de Praga. Universidad Nacional Autonóma de México, IIA, IIE, IIH.

Gutiérrez, M. de la L., \& Hyland, J. (2006). Complejidad social y simbolismo prehistórico. El fenómeno mural en la sierra de San Francisco, Baja California Sur. In M. del P. Casado \& L. Mirambel (Eds.), EL arte rupestre en México: 1990-2004 (pp. 73-94). Instituto Nacional de Antropología e Historia.

Harris, M. (1982). El Materialismo cultural. Madrid: Alianza editorial.

Harris, M. (2011). Antropología Cultural (Tercera ed). Madrid: Alianza editorial.

Kirchhoff, P. (2013). Introducción. In E. Acosta (Ed.), Noticias de la Península Americana de California (pp. XIX-XLV). Archivo Histórico Pablo L. Martínez.

Laylander, D. (1987). Una exploración de las adaptaciones culturales prehistóricas en Baja California. Estudios Fronterizos, V(14), 117-124.

Laylander, D. (2001). The question of Baja California's prehistoric isolation: evidence from traditional narratives. In Memorias: Balances y Perspectivas de la Antropología e Historia de Baja California (pp. 73-83). Instituto Nacional de Antropología e Historia.

Laylander, D. (2016). Fuentes y estrategias para la prehistoria de Baja California. San Diego State University.

León-Portilla, M. (2000). La California mexicana. Ensayos acerca de su historia. UNAM - UABC.

León-Portilla, M. (2007). Introducción a la Historia de la Antigua o Baja California de Francisco Xavier Clavijero. In M. León-Portilla (Ed.), Historia de la Antigua o Baja California (pp. VII-XXXII). Editorial Porrúa. 
Magaña, M. (2014). Los Libros de misión en la Baja California: fuentes históricas y patrimonio mueble. Meyibó, 4(8), 39-74.

Martínez, P. (2011). Historia de Baja California. La Paz: Archivo Histórico Pablo L. Martínez.

Massey, W. (1949). Tribes and Languages of Baja California. Southwestern Journal of Anthropology, 5(3), 272-307.

Mathes, M. (1980). La adaptación del bajacaliforniano al medio ambiente desde la antiguedad, hasta mediados del siglo XIX. Calafía, IV(2), 31-34.

Mathes, M. (2010). Testimonio Etnohistórico. In D. Laylander, J. Moore, \& J. Bendímez (Eds.), La Prehistoria de Baja California. Avances en la arqueología de la Península Olvidada. (pp. 53-83). Instituto Nacional de Antropología e Historia.

Messmacher, M. (1997). La busqueda de los signos de Dios. Ocupación jesuita de la Baja California. Fondo de Cultura Económica.

Mixco, M. (1978). Cochimí and proto Yuman: Lexical and Syntactic Evidence for a New Languaje Family in Lower California. University of Utah Anthropological Papers, (101).

Mixco, M. (2010). Las lenguas Indígenas. In D. Laylander, J. Moore, \& J. Bendímez (Eds.), La Prehistoria de Baja California. Avances en la arqueología de la Península Olvidada. (pp. 31-52). Mexicali: Instituto Nacional de Antropología e Historia.

Rebman, J., \& Roberts, N. (2012). Baja California. Plant Field Guide (3rd ed.). San Diego: San Diego Natural History Museum.

Rodríguez, R. (2002). Cautivos de Dios. Los cazadores-recolectores de Baja california durante el periodo colonial. CIESAS, Instituto Nacional Indigenista.

Rosales-Lopéz, A., \& Fujita, H. (2000). La antigua California prehispánica: la vida costera en El Conchalito. Instituto Nacional de Antropología e Historia.

Uriarte, M. (2013). Historia y Arte de la Baja California. México. México: Universidad Nacional Autonóma de México Instituto de Investigaciones Históricas.

Varela, L. (2016). La California jesuita (Salvatierra, Venegas, Del Barco, Baegert). La Paz, B. C. S.: Archivo Histórico Pablo L. Martínez. 